\title{
AN ANALYSIS OF APPLICATION OF KEY FINANCIAL RATIOS FOR HUMAN RESOURCES VALUATION IN ORGANIZATIONS
}

\author{
Dr. Govind Patra \\ Professor in Finance, \\ Lovely Professional University, Jalandhar, Punjab, India
}

\begin{abstract}
Knowledge workers are now most crucial resources for modern business organizations which keep all other assets men, money, machine and materials operative. However, with growing emergence of knowledge economy, the traditional valuation methods has been put into question due to the non-inclusion of Human capital as a major part offirm's total value in balance sheet. The value of Human Resources in an organization should be measured for sustainable growth of the organization since it plays the role of motivational tool, efficiency measure yardstick and cost clarification. Human Resource Accounting (HRA) measures and reports the value of employees in $B / S$ which helps management take strategic decisions related to human resources in order to enhance efficiency and productivity. Unlike other category of assets, valuation of Human Assets seems to be complex. One shortcoming is availability of good valuation model since all the models developed till now suffer from limitations in one form or other. This paper tries to suggest a comprehensive, easy to use and relatively limitation free valuation ratio model termed Intellectual Capital Value (ICV), which is modification of existing ratio based models available. For this, all the financial ratios useful for human resources valuation are analyzed first and then the new model termed Intellectual Capital Valuation (ICV) prescribed.
\end{abstract}

Key word: ICV, Intellectual Capital, MC, Human Resource Valuation, Human Resource Accounting, VAIC, CIV, EVA, Tobin's q.

Cite this Article: Dr. Govind Patra, An Analysis of Application of Key Financial Ratios for Human Resources Valuation in Organizations, International Journal of Management, 10 (4), 2019, pp. 24-35.

http://iaeme.com/Home/issue/IJM?Volume=10\&Issue $=4$

\section{INTRODUCTION}

Late twentieth and twenty first century witnesses rapid transformation of industrial economy to a knowledge-based economy as a result of the emergence of new technologies and IT. So, the importance of human resources as a key element for determination of success of any organization can not be undermined. HRA is a systematic process of identifying, measuring, recording and communicating information about human resources value for facilitation of 
effective management within an organization. In the knowledge based industries such as IT, firms recognize people as a key resource to gain competitive edge over their peers. In India, however there are only few rules and regulations (Section 217 of Company's act, 1956; SEBI Guidelines) which mandate firms to disclose very limited information about human resources in their annual reports. However, many Indian IT firms voluntarily disclose much more information about their human resource value than is mandatorily required. Human asset involves continuous significant amount of investment for the organization. But it does not reflect in balance sheet rather than showing just a mere operating expense in the P\&L statement as per conventional accounting system. Many HR valuation models have been developed for last half a century but still it is in the nascent stage due to complexities involved and for not having an easy-to-use, comprehensive and understandable model thereon. We are aware that there are 4 M's like Men, Money, Machine and Materials associated with any organization. Of the 4 M's, the other three are treated as assets to find a place on the the Balance Sheet. However the fourth and most important $\mathrm{M}$, i.e Men are still neglected to find a place in financial statements. The aim of human resource accounting is to depict the potential of human resources in monetary terms. The benefits of adopting human resource accounting are magnified. It helps an organization to take managerial decisions based on the availability and the necessity of human resources. When the human resources are quantified, it gives the investors and other stakeholders true insight about the affairs of the organization and it's future potential. It was only in the mid-1990s, after Infosys started valuing its employees, that the concept gained popularity in India. Intellectual capital is an intangible value driver in an organization that brings about future benefits. Modern business environment is quite dynamic and the business organizations are exposed to numerous changes and challenges on a continual basis. This is through intellectual capital only, the firms could able to quickly adapt to such changes and remain competitive in the market. HRA can also be viewed as an important tool for investors in judging the investment worthiness of the company. Thus, humans resources through HRA are fast changing to a resource, an asset or a capital from just an expenditure or a cost. Since the survival, growth and profits of the organizations are perceived to be dependent more on the intellectual assets than the physical assets in the knowledge era, there arises a serious need to determine HR investments and value.

Basically, Intellectual Capital (IC) is segmented into three components : Human Capital, Structural Capital and Relational Capital. The definition, description and meaning of each component are mentioned below :

Human capital is the major component of intellectual capital which includes professional competence, social competence, employee motivation and leadership quality. Professional competence is the experience and the expertise through training, higher education opportunities, practical experience, courses and seminars. Social competence includes interpersonal skills, ability to communicate and cooperation amongst employees (Swart, 2006) which in turn leads to higher level of performance and productivity. Organizations invest in motivating employees through various methods such as fair compensation, decision making capacity, bonus, commissions and promotion. Leadership includes the ability to develop and communicate strategy and vision as well as implement it. Research by Swart (2006) shows that human capital is critical since it is a strategic source of creativity and innovation in a business. Proper management of the human capital could help in generating other intellectual assets in a business.

Structural capital includes product innovation, corporate culture, management instruments, IT and explicit knowledge, internal cooperation, and process optimization. Product innovation ensures launching new products which enhances the competitiveness and survival of the firm. This leads to patents and copyrights among others. Corporate culture relates to values and 
norms that influence knowledge transfer and job interactions. A good corporate culture ensures that there is compliance to policies and it sets the habit of innovation and improvement. Management instruments tend to support the effort of leaders and influences the way decisions are communicated to every employee. Process optimization relates to continuous improvement of internal procedures and processes. Internal cooperation refers to how workers in the organization are able to cooperate and exchange information. Structural capital include various elements such as processes, systems, structures, the intellectual assets, proprietary software, computer programs, the databases, the organizational culture, trademarks, patents among others (Choong, 2008). Structural knowledge remains in the organization even when the employees leave the organization. It tends to make the people work better and in a smarter way.

Relational capital includes relationship with customers, suppliers, public, investors and other stakeholders of the firm. Aspects such as good customer service enhances strong bonding with customers. Businesses pursue seriously to improve investor relationship such as providing accurate information to investors to aid them in decision making. For purposes of achieving a competitive advantage, long-term and strong relationships to every stakeholder is very crucial.

\section{LITERATURE REVIEW}

Stewart (1991) argued intellectual capital can be utilized to create competitive advantage. He defined intellectual material as the aggregate of an organization's patents, processes, employees' skills, technologies, information about customers and suppliers, and old-fashioned experience. Edvinsson and Sullivan (1996) informed intellectual capital as knowledge can be converted into value for organizations. Roos and Roos (1997) view intellectual capital as the most important source for competitive advantage. They argued that a systematic approach to measure intellectual capital is increasingly essential now for companies regardless of the industry, size, age, ownership, and geographical dimensions.

Generally, researchers have divided the concept of intellectual capital into three main constructs (Bontis, Chua, \& Richardson, 2000). Bontis (1996; 1998; 1999), Roos et al. (1998), Stewart (1991; 1997), Sveiby (1997), Edvinsson and Malone (1997) defined intellectual capital as composition of human, structural, and relational capital.

Elaborating on the difference between intellectual capital and knowledge, Roos et al. (1998) argued While knowledge is a part of IC, IC is much more than knowledge. Brands, trademarks and relationship management with external parties (trade distributors, peers, customers, local communities, stakeholders in general and the like) are all dimensions of value creation (p. 24). Bontis (1999) also observed human capital is important since it is the source of innovation for organizations.

Structural capital is the knowledge that stays in the firm when employees go home for the night (Ordonez de Pablos, 2004; Roos et al., 1998). Therefore, organizations usually have residual claim on it. Employees provide structural capital for the company and the company is the residual owner of it. Structural capital comprises all kinds of "knowledge deposits" such as organizational routines, strategies, process handbooks and databases (Boisot, 2002; Ordonez de Pablos, 2004; Walsh \& Ungson, 1991).

Relational capital comprises the knowledge embedded in all the relationships an organization develops, whether it is with customers, competitors, suppliers, trade associations or government bodies (Bontis, 1999). One of the main categories of relational capital is customer capital that signals market orientation of organizations.

According to Marr et al. (2004), organizations need to recognize and manage their knowledge assets in order to excel and improve business performance. Chen et al., 2005; Firer \& Williams, 2003; Riahi-Belkaoui, 2003; have argued that if the market is efficient, investors will put higher value on firms with greater intellectual capital. Furthermore, Chen et al., (2005) 
maintained that if intellectual capital is a valuable resource for a firm's competitive advantage, it will contribute to market valuation and financial performance.

Using Taiwanese listed companies and applying VAIC intellectual coefficients, Chen et al. (2005) observed human capital and structural capital have a positive impact on a firm's financial performance and market value. In addition to using VAIC coefficients as proxies for intellectual capital components, they also utilized R \& D expenditures as a proxy variable for structural capital and found a significant relationship between R \& D expenditures and profitability.

Investigating Austrian industries, Bornemann (1999) found there exists a positive correlation between human capital and financial performance in an organization. According to Fajana (2002), a well-developed system of human resource accounting could contribute significantly to internal decisions by management and external decisions by investors. Rao (2005) opined that human capital accounting helps potential investors judge a company better on the strength of human assets. Thus, if two companies offer the same rate of return on capital employed, information on human resources can help investors decide which company to choose for investment.

\section{OBJECTIVES}

Human Resources valuation is still under development. Many researchers have undertaken to fulfill various objectives relating to human resource accounting in financial statements. The objectives we delineate here are:

i) To assess certain financial ratios useful for human resources valuation;

ii) To depict the limitations of such ratios in valuing human assets;

iii) To develop a ratio based comprehensive, easy to use model for human asset valuation named Intellectual Capital Value (ICV);

\section{HUMAN RESOURCES VALUATION MODELS UTILIZING FINANCIAL RATIOS}

Return on Assets (RoA) and Market Capitalization (MC) Methods are calculation of certain financial ratios used to measure intellectual capital value at organizational level.

\subsection{Market Capitalization Methods}

Sveiby (2007) mentioned the ratios under Market Capitalization methods offer some ways to calculate the value of intellectual capital or intangible assets through the difference between the firm's market capitalization and its stockholder's equity. A common characteristic of MC methods is that they all use capital market values to estimate the aggregate value of IC. Prominent methods falling under this category are Tobin's q, Market-to-Book Value ratio and Stock Market Capitalization to GDP Ratio which is in other words known as Buffet Indicator.

\subsubsection{Market Capitalization}

Many famous authors in the field of human resource valuation (Brooking, 1996; Edvinsson, 2000; Edvinsson \& Malone, 1997; Stewart, 1997) argued that the difference between market value of the company's shares \& debt and book value of assets reported in the balance sheet can be associated with the value of intellectual capital. Market capitalization of a firm is simply measured by multiplying no. of outstanding shares with current market price of the stock. Total wealth of the firm is sum of tangible physical assets, intangible financial assets, and value of intellectual capital which is sum total of human capital, structural capital and relational capital. Since, physical and financial assets are already shown in asset side of balance sheet, so subtracting total assets from market capitalization of firm, will give the total value of intellectual capital for the firm. 
The limitations of this method is that since market capitalization changes very frequently with change in market price of share, but the asset value doesn't change so much and so often, means that value of intellectual capital (IC) continually changes.

\subsubsection{Tobin's $Q$}

While Tobin is often credited as creator of q ratio, but it was first designed and reported by economist Nicholas Kaldor in an academic publication in 1966.. The Tobin's Q ratio measures market value of a company divided by its asset replacement cost. Thus, equilibrium is reached when market value equals replacement cost or Tobin's Q equals 1.

\section{Tobin's Q = Total Market Value of Firm / Replacement Cost of Assets}

Replacement cost refers to the cost of replacing an existing asset based on its current market price. It may be less or more than the acquisition or purchase price. Since the replacement cost is difficult to estimate, so it may be approximated to book value of equity and debt.

Tobin's Q=Market Value of Equity and Debt / Book Value of Equity and Debt

Assuming market value and the book value of a company's liabilities/debt are same since market value of debt hardly changes, the formulae can further be simplified to :

Tobin's Q= Market Value of Equity / Book Value of equity

$Q$ values of less than one means cost to replace a firm's assets is greater than the stock market value and hence the stock is undervalued. Conversely, a high Q value of more than 1 implies that a firm's stock is more expensive than the replacement cost of its assets and hence overvalued.

Stewart (1997) argued that even though Tobin's q was not originally developed to be a measure of intellectual capital but it actually signals a good indicator of intellectual capital value. High ' $q$ ' ratios signal the firm might be earning extraordinary returns on the basis of its intellectual capital and may not be always overvalued. Two firms may have similar fixed assets, but one who has superior people, process, systems and customers will be able to earn more returns." (Stewart, 1997, p. 226).

Bontis (1998) supported this argument by stating that Tobin's q value is different across different industries. Firms in the software industry enjoy an average Tobin's q ratio of close to seven due to their high degree of intellectual capital value. However, firms in traditional steel and power industry might have an average ratio of close to one due to their reliance on physical capital and labour.

The limitation of Tobin's q is to derive value for replacement cost of assets. Market values of stocks and bonds can be determined from capital market data which is readily available. However, unless there is a ready made market for used assets of that industry, it is difficult to find out replacement cost.

\subsubsection{Market Value to Book Value Ratio}

Chen \& Hwang (2005) argued that the market-to-book value ratio, as a reasonable measure to value IC, has received widespread attention from researchers in the field of IC. Supporting the ratio, Stewart (1997) argued that market- to-book value ratio is easy to understand and calculated easily. This ratio becomes very useful for comparison of performance of firms in the same industry. Furthermore, managers and other interested stakeholders would carry a better image if firm's market-to-book ratio is more than its peers in the same industry or rises over time (Stewart, 1997).

However, the limitations of this method as discussed earlier is that the market is volatile and share prices are subjected to frequent change in prices and quite sensitive to other economic and general conditions that are external to the organization. Secondly, depending upon depreciation rate and method used, the book value of the assets reported in the balance sheet 
might be either understated or overstated. Third and most important, there lies a speculative value and factors of supply and demand in securities traded in capital market and it becomes extremely difficult to segregate values attributable to intellectual capital and speculation out of excess of market value from book value.

\subsubsection{Buffet Indicator}

Buffet Indicator is named after famous investor and owner of Berkshire and Hathway, Warren Buffett who popularized this method. This is simply stock market capitalization to GDP ratio which is used to determine whether an overall market is undervalued or overvalued. It is simply calculated as stock market capitalization divided by Gross Domestic Product of the country. This ratio can be used as a measure of total value of human capital working in manufacturing and services sector organizations in a country.

This ratio is represented as $\mathrm{SMC} / \mathrm{GDP} \times 100$

Where, $\mathrm{SMC}=$ Stock Market Capitalization

GDP $=$ Gross Domestic Product

If the ratio falls between 50 and $75 \%$, the market is termed to be modestly undervalued. The market is considered to be fairly valued if the ratio falls in the range of 75 and $90 \%$ and modestly overvalued if it is between 90 to $115 \%$. However, this ratio is gradually increasing for most countries with the passage of time, development, advancement of technology and gradual conversion of traditional economy to knowledge economy. Usually, this ratio is more for developed world than developing and under developed countries. The average ratio for all countries globally in 2017 was $88.26 \%$. The highest value was assigned to Hongkong at $1274.13 \%$ and lowest value was observed in Costa Rica at 5.26\%. Ratio for US stands at $165.65 \%$. For some other significant countries this ratio stands at Japan (127.72\%), China $(71.18 \%)$ and Germany at $61.52 \%$.

In India, Market Cap to GDP Ratio $=\$ 2.12 \mathrm{tn} / \$ 2.716 \mathrm{tn} \times 100=78.05 \%$ for 2018

\subsection{Return on Assets (ROA) Methods}

Here the analysts develop an indicator in order to determine the efficiency or potential value of human capital. Some of the more applied methods under this category include Value Added Intellectual Capital Coefficient (VAIC), Calculated Intangible Value (CIV) and Economic Value Added (EVA). We have introduced here a comprehensive and easy to use model termed Intellectual Capital Value (ICV) through modification of existing models. These indicators can be applied for comparing companies for IC performance across similar industries.

\subsubsection{Value Added Intellectual Capital Coefficient (VAIC)}

Partially based on Skandia Navigator, Pulic (1998; 2000; 2004) had developed the Value Creation Efficiency Analysis, which measures the efficiency of the resources in organizations using data from published financial statements. Pulic (2004) argued that the model could very well be used to measure the value addition of intellectual capital. He argued that in the knowledge era, all traditional performance measurement parameters such as revenue, cost and profit need to be replaced by new measurement systems based upon value and efficiency. VAIC undertakes value addition as the most suitable indicator for business performance. As per this model, total assets in the organization are of two types : Capital \& Intellectual Capital. Capital is again subdivided into two parts : Physical (tangibles) and Financial (Intangibles). Again, the Intellectual Capital is subdivided into three parts : Human, Structural and Relational Capital.

Pulic (2000) calculated value-added and the values of three types of capital: human capital, structural capital, and capital employed. He noted that the value of human capital can be expressed by the labor expense. Structural capital equals the book value of the net assets of the firm (Firer and Williams, 2003). Pulic (2002) then calculated the ratio between each of these 
three forms of capital and value-added, resulting in capital employed efficiency (CEE), human capital efficiency (HCE), and structural capital efficiency (SCE). To conclude an overall measure of efficiency, Pulic (2002) adds the three efficiency measures:

$$
\begin{aligned}
\mathrm{VAIC} & =\mathrm{CEE}+\mathrm{ICE} \\
& =\mathrm{CEE}+\mathrm{HCE}+\mathrm{SCE} \\
& =\mathrm{CEE}+\mathrm{HCE}+\mathrm{CCE}+\mathrm{OCE} \\
& =\mathrm{CEE}+\mathrm{HCE}+\mathrm{CCE}+\mathrm{InCE}+\mathrm{PCE}
\end{aligned}
$$

Thus, as we see from the formula the VAIC coefficient is the sum of these following parameters:

1) Efficiency rate of capital employed - CEE (Capital Employed Efficiency)

2) Rate of effectiveness of human capital - HCE (Human Capital Efficiency)

3) Rate of structural capital efficiency - SCE (Structural Capital Efficiency)

4) Further SCE is decomposed into Customer Capital Efficiency (CCE) and Organizational Capital Efficiency (OCE)

5) Again OCE is divided into Innovation Capital Efficiency (InCE) and Process Capital Efficiency (PCE)

Value Added $(\mathrm{VA})=$ Output - Input

$$
=\text { Sales/Revenue }- \text { Cost of RM, Components \& Consumables }
$$

In other words, Total Value Added is :

$\mathrm{VA}=\mathrm{OP}+\mathrm{EC}+\mathrm{D}+\mathrm{A}$

$\mathrm{OP}=$ Operating Profit

$\mathrm{EC}=$ Employee Costs

$\mathrm{D}=$ Depreciation

$\mathrm{A}=$ Amortization

Efficiency of the financial capital employed can be obtained using the following formula:

$\mathrm{CEE}=$ capital employed efficiency coefficient $=\mathrm{VA} / \mathrm{TA}$

$\mathrm{VA}=$ value added

$\mathrm{TA}=$ Total assets of the company

VAIC considers expenses incurred for employees are investments not as costs. Thus, Human Capital Efficiency (HCE) is calculated as follows:

$\mathrm{HCE}=\mathrm{VA} / \mathrm{HC}$

$\mathrm{HCE}=$ Human capital efficiency coefficient for the company

$\mathrm{VA}=$ value added

$\mathrm{HC}=$ total salaries and wages for the company

Structural capital efficiency ( $\mathrm{SCE}$ ) is:

$\mathrm{SCE}=\mathrm{SC} / \mathrm{VA}$

$\mathrm{SCE}=$ structural capital efficiency for the company

$\mathrm{SC}=$ structural capital

$\mathrm{VA}=$ value added

Intellectual capital efficiency (ICE) is sum of coefficients of human and structural capital efficiency :

$\mathrm{ICE}=\mathrm{HCE}+\mathrm{SCE}$ 
Again following Skandia Navigator, structural capital is composed of customer capital and organizational capital. Further, organizational capital can be fragmented into innovation capital and process capital. Thus,

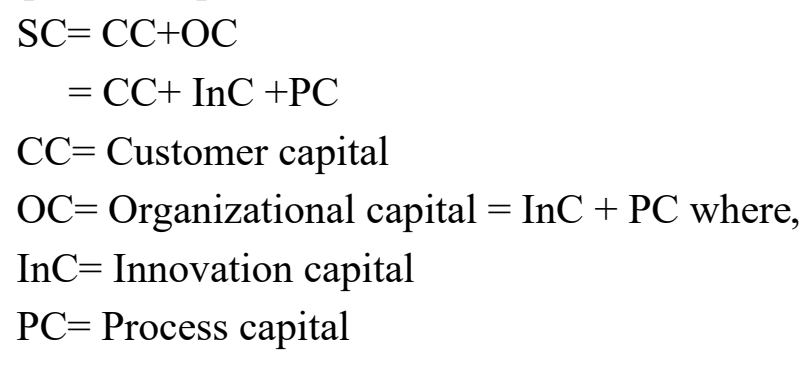

As we have already established, $\mathrm{SCE}=\mathrm{SC} / \mathrm{VA}$

$$
\begin{aligned}
& =(\mathrm{CC}+\mathrm{InC}+\mathrm{PC}) / \mathrm{VA} \\
& =\mathrm{CC} / \mathrm{VA}+\mathrm{InC} / \mathrm{VA}+\mathrm{PC} / \mathrm{VA} \\
& =\mathrm{CCE}+\mathrm{InCE}+\mathrm{PCE}
\end{aligned}
$$

Therefore, structural capital efficiency is the sum of efficiencies of customer capital plus innovation capital and process capital.

Now, marketing may be defined as developing and managing customer relationships. Therefore, marketing costs such as advertisement and promotional expenses can be used as a proxy for measurement of customer capital. Thus, Customer Capital Efficiency (CCE) may be measured as Marketing Expenses divided by Value Added.

\section{$\mathrm{CCE}=\mathrm{CC} / \mathrm{VA}=$ Marketing Costs/VA}

Further, Research and development expenses (R \& D) has been used extensively as a proxy for innovation capacity (Bosworth and Rogers, 2001). Thus, the efficiency of innovation capital is calculated in the following manner:

$\mathrm{InCE}=\mathrm{InC} / \mathrm{VA}=\mathrm{R} \& \mathrm{D} / \mathrm{VA}$

Process capital efficiency now simply equal to structural capital efficiency minus customer capital efficiency minus innovation capital efficiency.

So, PCE $=$ SCE - InCE - CCE

The limitations of VAIC model is that it does not properly segregates expenses from assets. It is believed that an asset offers long term benefit (Lev, 2000) but benefits accrued from an expense is restricted to an accounting period. Labor expenses may include expenses that are expected to bring benefits later (like training expenses or R\&D), but that is a minimal part of total expenses incurred for labour. Thus, this should not be treated as an asset. Andriesson (2004) notes that in case 'the operating income of a company is negative, structural capital becomes negative.' Further, it is important to note that if a company has limited net assets because of some big liabilities, capital used would be small or close to zero, and CEE and VAIC will become very large. Therefore, big liabilities can distort VAIC outcome. Andriessen (2004) stated that "I sympathize with Pulic's (2000) argument that we should not treat labor simply as an expense. I admire the work he and his team have done in creating awareness of the importance of intellectual capital, but I think the VAIC method is based on assumptions that can be seriously questioned."

\subsubsection{Calculated Intangible Value (CIV)}

CIV is a measure developed by NCI Research, an affiliation of Kellogg School of Business, to determine the fair market value of a firm's intangible assets. Stewart (1997) and Luthy (1998) mentioned that it becomes difficult for knowledge intensive firms to obtain loans from financial institution since usually they operate with a small tangible asset base and possess significant intangibles. Luthy (1998) argued that a knowledge based company with limited tangible 
resources can use the value calculated through this method as a leverage to negotiate with financial institutions for grant of loans. Now with the expansion of knowledge economy, banks and FIs are convinced that intangibles have the potential to generate more future cash flows than the cash generated from physical assets. Stewart (1997) explained the seven steps that are involved in calculating CIV:

Step 1: Calculate average pre-tax earnings over the past three years.

Step 2: Find the average year-end tangible assets for the same period from the balance sheet of the past three years.

Step 3: For the same three years, find the industry's average ROA.

Step 4: Multiply the industry-average ROA by the company's average tangible assets.

Step 5: Subtract the number from the pre-tax earnings to calculate excess annual earnings.

Step 6: Calculate post tax excess earnings by multiplying with (1-T) where $\mathrm{T}=\mathrm{Tax}$ Rate. The result thus obtained is the gross premium attributable to intangible assets.

Step 7: Calculate the present value of post tax excess return through discounting by company's WACC for perpetuity.

The resulting figure is the calculated intangible value (CIV), the assumption being constant earning to continue till perpetuity. It is a process of valuing a company's intangible assets. The limitation of this model is that it allocates a fixed value to intangible assets that does not change according to time and firm's market value. The second limitation is that CIV can't be computed for those firms having less than or equal to industry average RoA.

\subsubsection{Intellectual Capital Value (ICV)}

The steps to follow to calculate ICV is mentioned below. Firstly, we compute standardized earnings in order to smoothen out fluctuations in annualized earnings. Standardized earnings can be established through the average of the previous three years earnings including current year and projected earnings for the next three years period. ICV is the perpetually discounted standardized earnings that exceeds the expected returns on book assets utilizing an appropriate discount rate. Book assets here are segmented into physical tangible assets and financial intangible assets. ICV thus calculated is the value that can be attributed to the intangible assets or intellectual capital of the company. The method suggested may be utilized for comparison of enterprises belonging to same industry.

The objective of ICV is to analyze returns on physical and financial assets separately through which EVA of a firm's intellectual capital is determined. This when discounted by an appropriate discounting rate will provide us Intellectual Capital Value (ICV). The applicable discount rate suggested here is the risk free rate of return or the yield on T-Bills. Or a premium over inflation like nominal rate of return which is equal to inflation plus real rate of return. As per Fisher equation real rate of return remains constant at around $2 \%$ globally. Thus risk free rate of return and nominal rate of return will come very close to each other. WACC is not suggested for consideration of a suitable discount rate for human asset valuation since already human expenses are taken care of in P\&L statement.

Step 1 : Calculate Physical Asset value for a firm through the following method:

PA $=$ Physical Assets = FA+Inv-LTD where,

$\mathrm{FA}=$ Book Value of all Tangible Fixed assets

Inv = Inventory Value and

LTD $=$ Long Term Debt

Step 2 : Then calculate Financial Asset value for the firm 


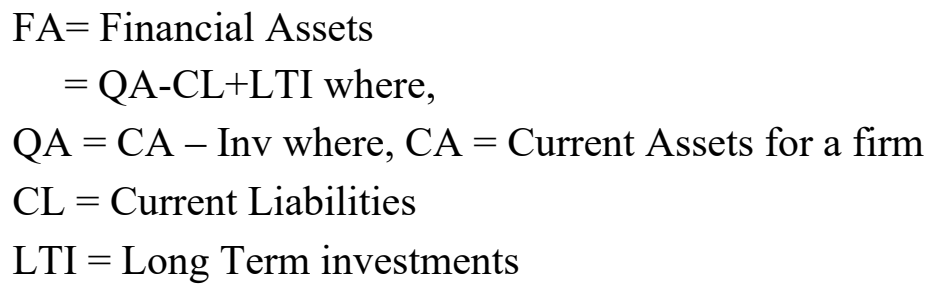

Step 3 : Calculate part of company's earnings generated through physical and financial assets separately utilizing industry average return on physical assets. Return on Govt. gilt edged securities may be assumed as a fair approximation for standardization of return on financial assets.

$$
\begin{aligned}
\mathrm{CE}_{1} & =\text { Part of company's earnings generated through Physical Capital } \\
& =\text { RoPA(Return on Physical Assets)*PA } \\
\mathrm{CE}_{2} & =\text { Part of company's earnings generated through Financial Capital } \\
& =\text { RoFA (Return on Financial Assets)*FA }
\end{aligned}
$$

Step 4 : Then excess return of firm's standardized pre-tax earnings over combination of $\mathrm{CE}_{1}$ and $\mathrm{CE}_{2}$ is derived which is additional earnings contributed by Intellectual capital (IC) or Intellectual Capital Earnings (ICE).

$$
\mathrm{ICE}=\mathrm{CE}-\left(\mathrm{CE}_{1}+\mathrm{CE}_{2}\right) \text { where } \mathrm{CE}=\text { Company's Standardized Operating Profit }
$$

Step 5 : Lastly, Intellectual Capital Value (ICV) is derived by discounting intellectual capital earnings through a suitable discount rate for perpetuity.

ICV = Intellectual Capital Value

$=\mathrm{ICE} / \mathrm{k}_{\mathrm{ic}}$ where, $\mathrm{k}_{\mathrm{ic}}=$ Applicable discount rate for discounting future earnings of human assets.

The limitation of this model is same as that of CIV. That it allocates a fixed value to intangible assets that does not change over time or according to firm's market value. The second limitation is that ICV can't be computed for those firms having less than or equal to industry average RoA.

\section{CONCLUSION}

Human Resource Accounting provides information about the value of human assets, which helps the top management to take strategic decisions based upon information available in a wide array of areas. The concept of human resource accounting is yet to gain momentum not only in India but also in entire globe. For the betterment of the organizations, it is essential to evaluate the worth of human resources in a systematic manner and record the information in financial statements to communicate their worth from time to time to the stakeholders. Organizations which are into research, creativity, science based or knowledge intensive, must value human resources to achieve optimum productivity, efficiency and success. Researchers have till now proposed numerous models for valuation of human assets but no model is free from limitations. In India, mostly Lev and Schwartz model with some modifications is utilized for HRA. Some knowledge based IT firms and mostly PSUs publish human resource value in their financial statements. The model uses several factors such as age, annual earnings up to retirement, retirement age of the employees \& cost of capital to value human assets of the company. However, it ignores productivity of employees, attrition rate and training expenses in its calculation. Initiative steps should be taken by individual governments as well as professional bodies at the national and international level in respect of formulation of specific accounting standard and development of suitable valuation model for measurement and reporting of value of human resources. 


\section{REFERENCES}

[1] Abeysekera, I and Guthrie, J, Human Capital Reporting in a Developing Nation, Faculty of Commerce - Papers, Retrieved from http://ssrn.com/abstract=1362110, 2004.

[2] Bartlett CA, Ghoshal S, Building competitive advantage through people. MIT Sloan Management Review 43 (2), 2002, pp 34-41.

[3] Bhattacharyya, D.K, Human Resource Research Methods. Oxford University Press, 2007

[4] Bullen, M.L. \& Novin, A.M, Human Resource Accounting and the Balanced Scorecard. http://www.clayton.edu/, November 09, 2009, 2000

[5] Bullen, M. L. and Eyler, K.A., Human resource accounting and international developments: implications for measurement of human capital, Journal of International Business and Cultural Studies, V(3), 2009, pp 1 - 16

[6] Arkadiusz Mironko, the Impact of Human Capital and Skill Availability On Attraction of Foreign Direct Investment (FDI) Into Regions within Developing Economies, International Journal of Management, 9 (3), 2018, pp. 139- 163.

[7] Dawson, C. (n.d.). Human Resource Accounting: From Prescription to Description?, Management Decision, Vol. 32, No. 6.

[8] Falmholtz, Eric G. \& Main, Erica D. (1999). Current Issues, Recent Advancements and Future Directions in Human Resource Accounting. Journal of Human Costing and Accounting, 4(1), 1999, pp 11-20.

[9] Flamholtz, E.G, Human Resource Accounting: Advances in Concepts, Methods, and Applications. New Delhi: Anmol Publication Pvt. Ltd, 1999

[10] Gupta, R.K, Human Resource Accounting. New Delhi: Anmol Publication Pvt. Ltd, 2003

[11] http://en.wikipedia.org/wiki/Human_resource_accounting

[12] http://www.articlesbase.com/human-resources-articles/human-resource-accounting-hrapractices-in-india-1272765.html

[13] Caroline, FX Sugiyanto, A.S. Kurnia and Firmansyah, Human Capital Category Interaction Pattern to Economic Growth of ASEAN Member Countries in 2015 by using GeoDa - Geo-Information Technology Datall. International Journal of Civil Engineering and Technology, 8(11), 2017, pp. 889-900.

[14] Lev. B. and Schwartz. A, "On the use of the Economic concept of Human Capital in Financial Statement, Accounting Review, January, 1971

[15] Lev, Baruch, Sharpening the Intangibles Edge [Electronic version].Harvard Business Review, 2004

[16] Liebowitz, J. and Wright, K, Valuation of Human Capital as a Component of Knowledge Assets Association for Information Systems AIS Electronic Library (AISeL) proceedings, 1998

[17] Miguel Angel Axtle Ortiz, Intellectual Capital (Intangible Assets) Valuation Considering The Context, Journal of Business \& Economics Research, Vol.-4, 2006

[18] Parameswaram R., and Jothi K, "Human Resource Accounting", Accounting, January 2005, pp. 867-874.

[19] Rana,K. and Maheshwari, S. K, A Marginal Monetary Worth (MMA): Human Valuation Model, Scientific Journal of Administrative Development, Vol. 3, 2005.

[20] Rao, D.P, Human Asset Accounting: An Evaluation of the Indian Practice. ASCI Journal of Management, 1993, 
[21] Rensis Likert and David G. Bowers, "Organization Theory and Human Resources Accounting”, Psychologist, Vol. 24, 1969, pp. 582-592.

[22] Roslender, R. and Dyson, J.R, Accounting for the worth of employees: A new look at an old problem. British Accounting Review, 24, 1992, pp 311-329.

[23] Shah, T. and Khedkar, A, Measuring Intangible Assets - Indian Experience, Indian Institute of Planning and Management (IIPM) Ahmedabad, 2006

[24] Srinivasan,Human Resources Accounting (HRA) Practices in INDIA, 2009

[25] Dr. A. Shameem Research. International Journal of Mechanical Engineering and Technology 2017, pp. 755-761.

[26] Turner,G, Human resource accounting - whim or wisdom? Journal of Human Resource Costing and Accounting, Vol 1, No 1, 1996, pp 63-73.

[27] Ulrich, Dave, \& Smallwood, Norm.,Capitalizing on Capabilities [Electronic version]. Harvard Business Review, June, 2004 